\title{
The Depiction of ECT in Egyptian Media
}

\author{
Emad Sidhom* \\ University of Cambridge, Department of Clinical Neurosciences, UK \\ *Corresponding author: Emad Sidhom, University of Cambridge, Department of Clinical Neurosciences, UK
}

\section{ARTICLE INFO}

Received: 幽 September 17, 2020

Published: 櫘 September 29, 2020

Citation: Emad Sidhom. The Depiction of ECT in Egyptian Media. Biomed J Sci \& Tech Res 30(5)-2020. BJSTR. MS.ID.005011.

\section{ABSTRACT}

Background: ECT is one of the most effective treatments in psychiatry. Yet, its use is quite limited as compared to its potential. The role of the media seems to have played an important role in curbing the use of ECT. The role of media in depiction of ECT has been studied in American films, British press, International and Hindi films. However, the region of North Africa and Middle East was not studied.

Aims: This paper aims at reviewing the portrayal of ECT in Egyptian films, to find out whether there was and representation of ECT. If so, to determine its accuracy and value.

Method: There is no clear database of Egyptian films and TV series that tackle mental health. A search was done on PubMed, Medline, EMBASE and Google Scholar using the terms ECT, electroconvulsive, Egypt, Arab, Arabic, films, media. Hence, the author had to revert to drawing from names of films to infer its relatedness to mental health, in addition to famous films and contemporary TV series that portrays mental illness and ECT specifically.

Results: Search on medical indexing search engines did not yield relevant results. There are at least 80 films and TV series that portrays mental illness of them 6 have direct relationship with ECT.

Conclusion: The depiction of ECT in Egyptian films is almost invariably negative, showing it as a painful and punitive measure.

\section{Introduction}

The effect of media on stigmatising ECT has been established, where it is usually negative due to its portrayal in the media[1]. The discussion stirred controversy about the role of ECT[2]. Authors wondered how deceptive the portrayal of ECT in the media is, especially the depiction of its use a punitive measure[3]. The representation of ECT in British press was deemed to be mostly negative[4]. American films tended to depict ECT in a negative way[5]. English-language films mostly portrayed ECT as a torture[6]. Authors lament the lack of correlation between narrative fiction and clinical reality[7]. Hindi films tended to depict ECT in a negative way, as a painful treatment with serious side effects [8]. Media lead to what has been titles as 'ECT deprivation syndrome' [9], where patients became reluctant to receive ECT due to the influences of the media. The same effect was noticed in medical students[10], where they became less supportive of ECT after watching scenes from films demonstrating ECT. Sienaert reviewed the image of ECT in international media and concluded that the image as almost invariably negative and inaccurate [11]. One area that did not seem to be examined which is Arabic-language films, particularly, Egyptian films which are one of the most influential film industries in the Middle East and North Africa. This paper examines notable films and TV series that either depicted ECT or discussed it.

\section{Materials and Methods}

I searched PubMed, Medline, EMBASE and Google Scholar using the terms ECT, electroconvulsive, Egypt, Arab, Arabic, films, media. Hence, the author had to revert to drawing from names of films to infer its relatedness to mental health, in addition to famous films and contemporary TV series that portrays mental illness and ECT specifically. I did also a generic search to find about Egyptian films that tackle mental illness in media however, the results 
were futile. I reviewed 80 Egyptian films and TV series that deal with mental disorder, with the aim of finding out about the image of Electroconvulsive Therapy (ECT) in the Egyptian media. The depiction of ECT appeared relatively late in the 1980's. It may have been chronologically related to the effect of anti-psychiatry and other American films that portrayed ECT negatively in the 1970's notably. Ken Kesey's One Flew over the Cuckoo's Nest.

\section{Results}

Six films and TV series were prominent in their demonstration of ECT, no films seem to have discussed ECT prior to the 1980's. These films and TV series are discussed here.

\section{Films}

'Khally Balak Men Aqlak' (1985), (Take care of your brain) is about a psychologist in field training for his post-graduate studies, who falls in love with one of the inpatients in a psychiatric hospital. The ECT was depicted as a punitive measure for behavioural excitation. Following an outburst of suspiciousness, the patient was dragged by staff as she declared that it is not her fault, yet she is the one who will receive the punishment. She started begging the doctor not to have it and was coerced to receive bitemporal ECT. Later, the main character who is a post-graduate trainee in psychology tries to put a pair of unprotected electric wires on his fingers to see the effects on electricity on him. Another scene depicts ECT as an awake immediate coercive measure without medical supervision. In a discussion during the film, ECT was described as a quick alternative to psychotherapy and medication. Towards the middle of the film, the main character smashes the ECT machine with a rod. In a second discussion, the main character calls ECT a 'crime' when it was administered without a doctor and asks the doctor whether ECT is the answer to any behavioural agitation. The response of the doctor about use of psychoanalysis and medication is that they are expensive, and they need training and specialists.

Resala Ila El-Wali (1998) (A message to the governor) is about a knight who goes to the future and was mistakenly thought to have a mental disorder and was admitted to a psychiatric hospital. In the hospital, the doctor screams 'electricity' in response to the main character's aggression. Restraints on the main character's body were put prior to administration. The machine operates via a large toggle switch that is actuated by a mechanical lever, and the electrodes were relatively small and placed in a bifrontal position. The scene is repeated about 3 times, almost in an identical manner. The social worker defending the main character says to the doctor that this is an unbearable torture beyond human limits. The doctor points at his bruised eyes hinting out that 'electricity' is a response to aggression and that this is not a patient. Toward the end of the film end, the doctor who orders ECT, gets electrocuted by the main character who used an identical large toggle switch. In '45 days' film (2007), ECT was depicted as last resort treatment. The ECT machine was a D/C fibrillator in the film.

\section{TV Series}

In a TV series 'La' (1998) (No) the ECT machine was used also a punitive measure that was used for behavioural coercion without medical supervision. In these works. The ECT was depicted in as a punitive instrument, with no anaesthesia, no medical supervision, and pain was central to its effect. The ECT was mostly referred to as 'electricity'. The ECT and/or the ECT doctor were punished at the end. These scenes in the media that may have contributed to the stigma of ECT in Egypt. In another TV series Al-Khanka (2016) a teacher is admitted to a psychiatric hospital and she was depicted to be thrown from a stretcher to a bed, ECT was given as a punitive measure, with a device that resembles a Stereo cassette player. The treating doctor was smoking in the treatment room. 'Ikhtifaa' TV series (2018) (Disappearance), ECT was not depicted but it was mentioned as a punitive measure, that has serious effects, causing 'memory damage'.

\section{Discussion}

ECT appeared in at least 6 films and TV series. In these the gender ratio was 1:1 The ECT depiction was almost invariably negative and punitive. None of the media representation presented a real ECT device. In all depictions, the main protagonist is the one who receives ECT and it is usually depicted as a painful form where subjects scream or grunt during the administration. Convulsions are not accurately depicted. One film and one TV series demonstrated the protagonist elevating both legs and extending them. Another film showed horizontal head movement. ECT was administered in the films by doctors who do not have time for psychoanalysis, or as a quick fix. In one TV series, the ECT was given on the commands of a police officer to subdue his wife who was wrongly diagnosed with mental illness, and she was promised to have further sessions if she complies.

\section{Conflict of Interest}

None Declared.

\section{References}

1. Griffiths C, O'Neill Kerr A (2019) 'Patients', Carers', and the Public's Perspectives on Electroconvulsive Therapy. Front Psychiatry 10: 304.

2. Anderson JF (1977) ECT and the media. British Medical Journal 2(6100): 1478.

3. Webber M (2008) Electroconvulsive therapy. BMJ 337: a2998.

4. Euba R, Crugel M (2009) The Depiction of Electroconvulsive Therapy in the British Press. JECT 25(4): 265-269.

5. McDonald A, Walter G (2001) The portrayal of ECT in american movies. J ECT 17(4): 264-274.

6. Matthews AM, Rosenquist PB, McCall WV (2016) Representations of ECT in English-language film and television in the new millennium. J ECT 32(3): 187-191.

7. McDonald A, Walter G (2009) Hollywood and ECT. International Review of Psychiatry 21(3): 200-206.

8. Andrade C, Shah N, Venkatesh BK (2010) The depiction of electroconvulsive therapy in Hindi cinema. J ECT 26(1): 16-22. 
9. Sabbagh K (1977) ECT and the media. British Medical Journal 2(6103): 1669-1670.

10. Walter G, McDonald A, Rey JM, Rosen A (2002) Medical student knowledge and attitudes regarding ECT prior to and after viewing ECT scenes from movies. J ECT 18(1): 43-46.

\section{ISSN: 2574-1241}

DOI: $10.26717 /$ BJSTR.2020.30.005011

Emad Sidhom. Biomed J Sci \& Tech Res

(C) This work is licensed under Creative

Submission Link: https://biomedres.us/submit-manuscript.php
11. Sienaert P (2016) Based on a True Story? The Portrayal of ECT in International Movies and Television Programs. Brain Stimul 9(6): 882891.

\begin{tabular}{ll} 
BIOMEDICAL & Assets of Publishing with us \\
RESEARCHES & - Global archiving of articles \\
\hline IsSN: $2574-1241$ & - Immediate, unrestricted online access \\
\hline
\end{tabular}

